\title{
Rancang Bangun Sistem Pakar dengan Metode Forward Chaining untuk Rekomendasi Pariwisata di Labuan Bajo Menggunakan iOS Platform
}

\author{
Leonardo Jeffry*1, and Rinabi Tanamal ${ }^{2}$ \\ 1,2Jurusan Sistem Informasi, Universitas Ciputra, Surabaya \\ e-mail: ${ }^{1 *}$ leonardojeffry23@ gmail.com, ${ }^{2}$ r.tanamal@ ciputra.ac.id \\ Submitted Date: May $30^{\text {th }}, 2020$ \\ Revised Date: July $30^{\text {th }}, 2020$ \\ Reviewed Date: June $29^{\text {th }}, 2020$ \\ Accepted Date: August $01^{\text {st }}, 2020$
}

\begin{abstract}
Nowadays many tourists like to travel. When on vacation the user is confused about where to go and whether it's good or not. When tourists want to take a vacation and the user must choose to do a tour and it turns out that it is not good in terms of good or bad attractions. So there is encouragement to help tourists to provide recommendations for good tourist places to visit. But now with so many online media to buy tickets, but the local guide is still rampant in maintaining tourism. This location with the presence of local guides who do not understand the price and when they are in Labuan Bajo the price of the user is still not right then it makes tourists confused. The existence of a problem raises the urge to make an application of an expert system that recommends tourist attractions in Labuan Bajo by using the Forward Chaining method. In making this application uses a rule based to process data on applications on iOS. And using mcgoo is used to create and process data taken from experts. This application can help tourists to find excellent places to travel. Because the purpose of the user to travel is to have fun if the user is confused to determine the existing location then this application will help the user determine the desired tourist attractions. This application also provides several tourist options such as tours on the sea, cities, or hills/mountains. The target of visitors is always less because tourists lack the desire to travel in Labuan Bajo because of the lack of recommendations on Labuan Bajo tourism. The results of research conducted by more foreign tourists who prefer to visit Labuan Bajo because local tourists prefer tourist destinations that are still crowded, such as Bali and Lombok. So that makes tourism in Labuan Bajo not yet an attraction for local tourists.
\end{abstract}

Keywords: Forward Chaining; Expert System; Destinasi Wisata; McGoo; iOS.

\begin{abstract}
Abstrak
Sekarang ini banyak wisatawan yang suka melakukan travelling. Pada saat liburan user bingung mau wisata ke mana saja dan apakah itu bagus atau tidak. Saat wisatawan ingin melakukan liburan dan user harus memilih untuk melakukan wisata dan ternyata kurang bagus dalam segi baik maupun buruknya tempat wisata tersebut. Sehingga ada dorongan untuk membantu wisatawan untuk memberikan rekomendasi tempat wisata yang bagus untuk dikunjungi. Namun sekarang dengan banyaknya media online untuk membeli tiket namun guide lokal masih merajalela dalam menjaga tempat pariwisata. Lokasi ini dengan masih adanya guide lokal yang kurang mengerti harga dan pada saat berada di Labuan Bajo harga user masih kurang tepat maka membuat bingung wisatawan. Adanya sebuah masalah memunculkan dorongan untuk membuat aplikasi mengenai sistem pakar yang merekomendasikan tempat wisata di Labuan Bajo dengan menggunakan metode Forward Chaining. Dalam membuat aplikasi ini menggunakan rule based untuk mengolah data pada aplikasi pada $i O S$. Dan menggunakan mcgoo digunakan untuk membuat dan mengolah data yang diambil dari para pakar. Aplikasi ini dapat membantu para wisatawan untuk mencari tempat yang sangat baik untuk melakukan travelling. Karena tujuan user melakukan travelling adalah untuk bersenang-senang jika user bingung untuk menentukan lokasi yang ada maka dengan adanya aplikasi ini maka akan membantu user menentukan tempat wisata yang diinginkan. Aplikasi ini juga memberikan beberapa pilihan wisata seperti wisata di laut, kota, maupun perbukitan/gunung. Target pengunjung selalu kurang karena wisatawan kurang memiliki keinginan untuk berwisata di Labuan Bajo
\end{abstract}


karena minim rekomendasi wisata Labuan Bajo. Hasil penelitian yang telah dilakukan lebih banyak wisatawan mancanegara yang lebih senang mengunjungi Labuan Bajo karena wisatawan lokal lebih menyukai destinasi wisata yang masih ramai seperti Pulau Bali dan Lombok. Sehingga membuat wisata di Labuan Bajo belum menjadi daya tarik bagi wisatawan lokal.

Kata Kunci: Forward Chaining; Expert System; Destinasi Wisata; McGoo; iOS.

\section{Pendahuluan}

Pariwisata adalah industri terbesar yang bisa menambahkan devisa negara. Sehingga pemerintah gemar untuk memasarkan pariwisata di negara mereka. Agar para wisatawan asing suka untuk dating ke negara tersebut melihat dan membantu memasarkan ke warga negara lain.

Labuan bajo adalah tempat wisata yang premium dan patut dikunjungi. Karena pariwisata di Bali, Lombok, dan lain sebagainya sudah terlalu sering dikunjungin oleh para wisatawan. Sehingga presiden Jokowi ingin meningkatkan lagi para wisatawan asing maupun lokal untuk datang ke Labuan Bajo. Karena masih banyak keindahan alam yang tidak kalah dengan Bali. Seperti wisata kota, gunung, maupun air (CNN Indonesia, 2019).

Tetapi wisatawan masih belum mengenal Labuan Bajo dikarenakan kurangnya marketing. Labuan Bajo sendiri masih kurangnya akses ke tempat wisata. Sehingga Labuan Bajo masih kurang disegani oleh para wisatawan asing. Sedangkan Bali sudah memiliki infrastruktur yang sangat baik dan lebih dikenal oleh para wisatawan.

Dengan melihat permasalahan ini ide membuat sebuah aplikasi sistem pakar yang dapat membantu wisatawan berkunjung pada destinasi wisata papua tersebut. Dengan adanya aplikasi ini user akan lebih mendapatkan informasi yang akurat dalam memperoleh harga tour guide.

Ide membuat aplikasi ini karena banyak wisatawan yang lebih mengenal Indonesia hanyalah bali sehingga wisatawan harus mengetahui masih banyak pulau di Indonesia yang bagus seperti pada aplikasi ini yang berupa pulau Labuan Bajo di Nusa Tenggara Timur. Dengan adanya aplikasi ini membuat wisatawan lebih mengenal Indonesia.

\section{Metodologi Penelitian}

\subsection{Sistem Pakar}

Sistem Pakar atau yang dikenal dengan istilah Expert System merupakan bagian dari beberapa domain yang dimiliki oleh Artificial Intelligence atau yang disebut dengan $A I$. Dan sistem pakar yang dipakai untuk pengetahuan tersebut diambil dari keahlian dan pengetahuan dalam memecahkan masalah dari bidang tertentu.
Domain yang bernama Sistem Pakar ini berfungsi sebagai suatu sistem yang dapat menyelesaikan permasalahan dengan penyelesaian pendekatan yang sangat berhasil dari pemrograman intelligent (Hayadi, 2018, p. 845). Arsitektur sistem pakar dapat dilihat di Gambar 1. (Munaiseche, Kaparang, \& Rompas, 2018, p. 306).

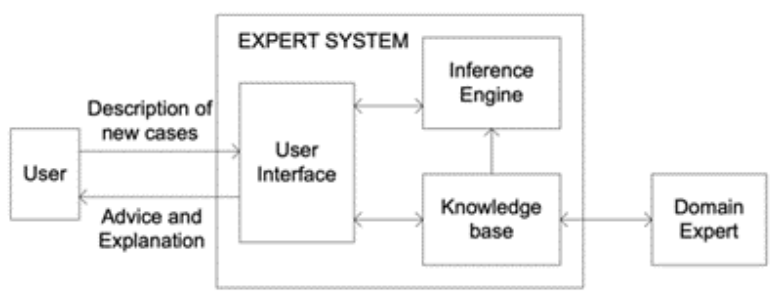

\section{Gambar 1. Arsitektur Sistem Pakar}

\subsection{Metode Forward Chaining}

Forward Chaining adalah metode yang digunakan untuk melacak dan diawali dengan informasi atau fakta dan proses mencocokkan dengan kaidah yang berlanjut terus sampai menimbulkan suatu kesimpulan. Dalam forward chaining, kaidah interpreter mencocokkan fakta atau statement dalam pangkalan data dalam situasi yang dinyatakan dalam bagian sebelah kiri atau kaidah $I F$. Bila fakta yang ada dalam pangkalan data itu sudah sesuai dengan kaidah $I F$, maka kaidah distimulasi (Putri, Santoso, Rabbani, \& Wulandari, 2014, p. 427).

\subsection{Mcgoo}

Program ini adalah aplikasi untuk membuat sistem pakar berbasis web secara online. McGoo sendiri merupakan hasil pengembangan lebih lanjut dari aplikasi ES-Builder 3.0 untuk Windows versi desktop menjadi versi web. Proyek tersebut menggunakan kerangka kerja pengembangan AJAX (McGuinness, 2015).

\section{4 iOS}

iOS atau yang dulu dikenal iPhone OS merupakan sistem operasi untuk produk smartphone yang dikembangkan oleh Apple inc dan bersifat open untuk semua. Sistem operasi ini 
dikhususkan untuk produk-produk smartphone yang digunakan untuk produk apple. Saat ini sistem operasi ini sudah mengalami banyak perkembangan sejak pertama diluncurkannya. (Apple, 2019).

\subsection{Xcode}

Xcode merupakan alat pemrograman yg dikeluarkan oleh Apple sebagai tempat untuk membangun aplikasi-aplikasi yg dapat digunakan di iPhone, iTV, dan perangkat lain yang dimiliki oleh Apple. Bahasa yg digunakan di Xcode ada dua, yaitu Objective-C dan Swift (Apple, 2015).

\subsection{Decision Tree}

Pohon Keputusan atau yang sering dikenal dengan istilah Decision Tree, salah satu metode klasifikasi yang paling sesuai dalam mengembangkan sebuah metode decision tree ini dan bertujuan untuk mengubah guna membantu dalam pengambilan keputusan yang tepat. Metode ini menggabungkan antara data dengan model sehingga membuat decision yang kompleks menjadi lebih simpel, spesifik, dan mudah (Nofriansyah, 2015).

\subsection{Triangulasi Sumber}

Triangulasi sumber data adalah metode pengumpulan data yang diambil dari beberapa sumber yang bertujuan untuk mendapatkan data yang valid. Digunakan untuk memberikan kejelasan mengenai data yang diberikan kepada narasumber. Benar atau tidaknya suatu data maka harus dilakukan traingulasi agar data yang dihasilkan teruji ke akuratannya (UMS, 2014).

\subsection{Observasi}

Observasi adalah metode pengumpulan data yang dilakukan dengan cara melakukan observe kepada objek yang akan diteliti.

\subsection{Wawancara}

Wawancara adalah metode pengumpulan data yang dilakukan dengan cara melakukan tanya jawab kepada objek yang akan diteliti. Wawancara adalah tahap lanjutan untuk memperoleh data-data yang dibutuhkan dalam penelitian ini.

\section{Implementasi, Hasil dan Pembahasan}

Implementasi yang saya lakukan pada pertama dilakukan adalah melakukan observasi. Setelah melakukan observasi lanjut melakukan wawancara kepada pakar untuk menemukan data yang sesuai. Hasil yang telah didapatkan dibuat pertanyaan dan membentuk pohon keputusan.

Pohon keputusan yang telah dirancang berdasarkan pertanyaan-pertanyaan yang telah dirangkum oleh peneliti yaitu:

1 Apakah mengiginkan untuk melakukan wisata di darat?

2 Apakah mengiginkan untuk melakukan wisata di bukit?

3 Apakah mengiginkan untuk melakukan wisata di goa?

4 Apakah mengiginkan untuk melakukan wisata berenang di goa?

5 Apakah mengiginkan untuk melakukan wisata air?

6 Apakah mengiginkan keinginan untuk melakukan snorkeling?

7 Apakah mengiginkan untuk melakukan diving?

8 Apakah mengiginkan untuk melakukan snorkeling dengan berjemur di pantai?

9 Apakah mengiginkan untuk melakukan diving dengan menikmati pantai?

10 Apakah mengiginkan untuk melakukan berenang biasa?

11 Apakah mengiginkan untuk melakukan berenang di pantai?

12 Apakah mengiginkan untuk melakukan berenang di air terjun?

13 Apakah anda memiliki keinginan untuk wisata antarpulau?

14 Apakah anda memiliki keinginan untuk trekking?

15 Apakah anda memiliki keinginan untuk hiking?

16 Apakah anda memiliki keinginan untuk hiking serta melihat berenang?

17 Apakah anda memiliki keinginan untuk melihat keindahan alam?

18 Apakah anda memiliki keinginan hiking serta melihat laut?

Lalu melakukan implementasi dan dimasukkan dalam McGoo setelah membuat rancangan pertanyaan dan jawaban yang akan dijadikan sebagai pohon keputusan akan diterapkan ke dalam aplikasi sistem pakar yang bernama McGoo Expert System. Dalam proses implementasi ke dalam MCGOO, aplikasi tersebut mempunyai 3 proses seperti Attribute, Value, dan Conclusion. Dalam hal ini, proses tersebut menggunakan aturan yang telah diterapkan yaitu dengan menggunakan pendekatan Forward Chaining. Aturan tersebut 
dapat memaparkan bahwa proses pada tahap awal di mana pengguna disuruh menjawab berbagai pertanyaan dan kemudian mendapatkan solusi dari permasalahan yang dihadapi. Setelah melakukan implementasi yang telah dilakukan maka dari McGoo diubah menjadi expert system dengan menggunakan Xcode.

Table 1. Hasil Pengujian Aplikasi

\begin{tabular}{|c|c|c|c|c|}
\hline No & $\begin{array}{c}\text { Jenis } \\
\text { Tempat } \\
\text { Wisata }\end{array}$ & Hasil Pengujian Aplikasi & Hasil Analisa Pakar & $\begin{array}{c}\text { Sesuai atau } \\
\text { Tidak } \\
\text { Sesuai } \\
\end{array}$ \\
\hline 1 & $\begin{array}{l}\text { Pulau } \\
\text { padar }\end{array}$ & $\begin{array}{l}\text { Pulau padar adalah pulau } \\
\text { yang memiliki keindahan } \\
\text { yang luar biasa karena kita } \\
\text { bisa melihat laut serta } \\
\text { menjadi objek utama. Tetapi } \\
\text { untuk melihat pemandangan } \\
\text { tersebut harus menaiki } 700 \\
\text { anak tangga. }\end{array}$ & $\begin{array}{l}\text { Pulau padar menjadi destinasi } \\
\text { utama wisatawan jika berkunjung } \\
\text { ke Labuan Bajo. Sehingga jika } \\
\text { mengunjungi wisata pulau destinasi } \\
\text { utama yaitu pulau padar karena } \\
\text { memerlukan waktu yang lama } \\
\text { untuk mencapai puncak. }\end{array}$ & Sesuai \\
\hline 2 & $\begin{array}{l}\text { Pulau } \\
\text { rinca }\end{array}$ & $\begin{array}{l}\text { Pulau rinca sangat dipadati } \\
\text { wisatawan karena menjadi } \\
\text { tempat yang menarik karena } \\
\text { wisatawan dapat melihat } \\
\text { Komodo dengan mudah. }\end{array}$ & $\begin{array}{l}\text { Pulau rinca selalu dipadati dengan } \\
\text { pengunjung/wisatawan } \\
\text { mancanegara karena lebih mudah } \\
\text { untuk melihat komodo } \\
\text { dibandingkan datang ke pulau } \\
\text { komodo. Karena pulau rinca lebih } \\
\text { kecil daripada Pulau Komodo. }\end{array}$ & Sesuai \\
\hline 3 & $\begin{array}{l}\text { Pulau } \\
\text { Kalong }\end{array}$ & $\begin{array}{l}\text { Pulau Kalong memiliki } \\
\text { keindahan yang luar biasa } \\
\text { karena di pulau kalong } \\
\text { ditinggali oleh berbagai jenis } \\
\text { kelelawar yang terdiri dari } \\
\text { berbagai ukuran. Selain itu } \\
\text { pulau kalong juga memiliki } \\
\text { flora dan keindahan bawah } \\
\text { laut }\end{array}$ & $\begin{array}{l}\text { Pulau Kalong terletak di antara } \\
\text { gugusan pulau pulau kecil di } \\
\text { kawasan Taman Nasional Komodo, } \\
\text { Pulau Kalong merupakan tempat } \\
\text { bersarang jutaan kelelawar dengan } \\
\text { berbagai ukuran. Beberapa pulau } \\
\text { kecil yang ada di dalam area Taman } \\
\text { Nasional Komodo memiliki } \\
\text { karakteristik sendiri sehingga pulau } \\
\text { kecil ini memiliki keindahan di } \\
\text { daratan ataupun di bawah lautnya. }\end{array}$ & Sesuai \\
\hline 4 & $\begin{array}{l}\text { Pantai } \\
\text { Pede }\end{array}$ & $\begin{array}{l}\text { Pantai pede yaitu Pantai yang } \\
\text { terkenal di Labuan Bajo } \\
\text { sehingga tidak memerlukan } \\
\text { waktu yang banyak untuk ke } \\
\text { pantai. }\end{array}$ & $\begin{array}{l}\text { Pantai pede Sering didatangi oleh } \\
\text { pengunjung dan tidak memerlukan } \\
\text { waktu yang banyak untuk kesana. } \\
\text { Tetapi tetapi harus naik kapal untuk } \\
\text { ke goa. Sehingga memerlukan } \\
\text { biaya yang cukup besar. }\end{array}$ & Sesuai \\
\hline 5 & $\begin{array}{c}\text { Goa } \\
\text { Cermin }\end{array}$ & $\begin{array}{l}\text { Goa cermin adalah salah satu } \\
\text { wisata yang ada di Labuan } \\
\text { Bajo di goa cermin kita dapat } \\
\text { melihat refleksi wajah kita di } \\
\text { batu cermin ketika ada sinar } \\
\text { yang masuk. }\end{array}$ & $\begin{array}{l}\text { Goa Batu Cermin adalah salah satu } \\
\text { obyek wisata yang unik yang } \\
\text { terdapat di Labuan Bajo. Sinar akan } \\
\text { dipantulkan oleh dinding- } \\
\text { dindingnya sehingga refleksi } \\
\text { tersebut mirip seperti sinar matahari } \\
\text { yang memantul di cermin. Itu } \\
\text { sebabnya, goa ini diberi nama batu } \\
\text { cermin. Seorang arkeolog } \\
\text { menemukan goa ini pada tahun } \\
1951 \text {. }\end{array}$ & Sesuai \\
\hline
\end{tabular}




\begin{tabular}{|c|c|c|c|c|}
\hline 6 & $\begin{array}{c}\text { Pantai } \\
\text { pink }\end{array}$ & $\begin{array}{l}\text { Pantai pink juga merupakan } \\
\text { destinasi yang harus bagi } \\
\text { wisatawan untuk snorkeling. }\end{array}$ & $\begin{array}{l}\text { Pantai pink sangat senang didatangi } \\
\text { wisatawan karena keunikan } \\
\text { pasirnya yang berwarna pink serta } \\
\text { snorkeling. Pantai pink juga } \\
\text { disukai oleh wisatawan untuk } \\
\text { berjalan di pantai }\end{array}$ & Sesuai \\
\hline 7 & Manjarite & $\begin{array}{l}\text { Manjarite sangat senang } \\
\text { dikunjungi wisatawan karena } \\
\text { wisatawan dapat melakukan } \\
\text { snorkeling serta dapat } \\
\text { berjalan di } \\
\text { pantai. }\end{array}$ & $\begin{array}{l}\text { Manjarite merupakan pulau pribadi } \\
\text { yang dapat digunakan wisatawan } \\
\text { untuk snorkeling serta dapat } \\
\text { berjalan di pantai. Dengan } \\
\text { keindahan alam yang } \\
\text { sangat luar biasa. }\end{array}$ & Sesuai \\
\hline 8 & $\begin{array}{c}\text { Pulau } \\
\text { Kanawa }\end{array}$ & $\begin{array}{l}\text { Pulau kanawa sangat suka } \\
\text { dikunjungi oleh wisatawan } \\
\text { terutama yang senang untuk } \\
\text { snorkeling serta diving untuk } \\
\text { melihat keindahan bawah } \\
\text { laut. }\end{array}$ & $\begin{array}{l}\text { Pulau kanawa sangat suka } \\
\text { dikunjungi oleh wisatawan baik } \\
\text { yang senang snorkeling serta diving } \\
\text { sangat suka mengunjungi pulau ini } \\
\text { karena keindahan bawah laut. Pada } \\
\text { pulau kanawa ini wisatawan akan } \\
\text { melihat pemandangan yang sangat } \\
\text { indah di pulau tersebut. }\end{array}$ & Sesuai \\
\hline 9 & $\begin{array}{c}\text { Taka } \\
\text { Makassar }\end{array}$ & $\begin{array}{l}\text { Taka Makassar sangat } \\
\text { disukai wisatawan yang } \\
\text { senang diving karena } \\
\text { keindahan bawah lautnya } \\
\text { serta di tempat ini hanya } \\
\text { digunakan untuk diving. }\end{array}$ & $\begin{array}{l}\text { Taka Makassar sangat banyak } \\
\text { dikunjungi oleh wisatawan yang } \\
\text { sangat senang untuk melakukan } \\
\text { diving karena bawah laut sangat } \\
\text { indah. Taka makassar juga } \\
\text { memiliki hewan hewan yang sangat } \\
\text { unik serta menjadi ketertarikan } \\
\text { wisatawan yang melakukan diving. }\end{array}$ & Sesuai \\
\hline 10 & $\begin{array}{l}\text { Cunca } \\
\text { Wulang }\end{array}$ & $\begin{array}{l}\text { Cunca wulang adalah air } \\
\text { tejun yang berada di Labuan } \\
\text { Bajo yang sangat indah dan } \\
\text { sering dikunjungi wisatawan } \\
\text { hanya untuk melihat } \\
\text { pemandangan serta berenang. }\end{array}$ & $\begin{array}{l}\text { Cunca wulang adalah air tejun yang } \\
\text { berada di Labuan Bajo yang sangat } \\
\text { indah dan sering dikunjungi } \\
\text { wisatawan hanya untuk melihat } \\
\text { pemandangan serta berenang. } \\
\text { Untuk menuju ke tempat ini tidak } \\
\text { lama. }\end{array}$ & Sesuai \\
\hline 11 & $\begin{array}{c}\text { Bukit } \\
\text { Amelia } \\
\text { Sea }\end{array}$ & $\begin{array}{l}\text { Bukit Amelia Sea sangat } \\
\text { senang dikunjungi wisatawan } \\
\text { karena dapat melihat } \\
\text { pemandangan serta dapat } \\
\text { memancing. }\end{array}$ & $\begin{array}{l}\text { Bukit Amelia Sea sangat senang } \\
\text { dikunjungi wisatawan karena dapat } \\
\text { melihat pemandangan serta dapat } \\
\text { memancing }\end{array}$ & Sesuai \\
\hline 12 & $\begin{array}{c}\text { Goa } \\
\text { Rangko }\end{array}$ & $\begin{array}{l}\text { Goa Rangko merupakan goa } \\
\text { yang tidak kalah menarik } \\
\text { bagi wisatawan di Labuan } \\
\text { Bajo karena di dalam goa ini } \\
\text { terdapat genangan air yang } \\
\text { digunakan wisatawan untuk } \\
\text { berenang. }\end{array}$ & $\begin{array}{l}\text { Goa Rangko ibarat sebuah kolam } \\
\text { renang pribadi yang menawarkan } \\
\text { keheningan bagi siapapun yang } \\
\text { mampir untuk berenang dengan air } \\
\text { yang ada di dalam goa. Goa } \\
\text { Rangko Nusa Tenggara Timur bisa } \\
\text { diibaratkan sebagai kolam renang } \\
\text { pribadi yang nyaman. }\end{array}$ & Sesuai \\
\hline
\end{tabular}

Pengujian akurasi yang dilakukan peneliti menggunakan objek dengan menggunakan observasi tempat wisata di Labuan Bajo serta wawancara dengan pakar di sana. Peneliti dapat melakukan perbandingan hasil dilakukan dengan decision tree yang telah dibuat. Melakukan 
pengujian dilakukan pada tempat wisata di Labuan Bajo untuk melihat kondisi wisata serta menanyakan sejarah maupun informasi tentang tempat wisata di Labuan Bajo.

Menurut hasil yang dilakukan oleh peneliti beberapa jenis wisata di Labuan Bajo dapat dilihat masih banyak orang lokal Labuan Bajo serta wisatawan mancanegara yang lebih banyak untuk melakukan wisata di sana. Serta tidak banyak wisatawan yang kebingungan untuk memilih wisata di mana yang akan user pilih di Labuan Bajo. Timbul dorongan untuk melakukan banyak sekali riset serta observasi yang dapat mendukung pembuatan aplikasi ini.

Tempat wisata yang banyak dikenal wisatawan hanya beberapa saja seperti pulau Padar, pantai Pink dan pulau Rinca. Hal ini disebabkan karena kurangnya eksplorasi dari wisatawan pada saat berkunjung ke Labuan Bajo. Oleh karena itu, untuk melakukan berbagai riset serta melakukan foto untuk beberapa tempat yang jarang dikunjungi wisatawan.

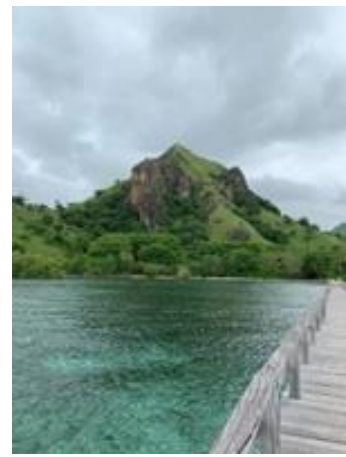

\section{Gambar 2 Manjarite}

Tempat wisata lain seperti sawah Lingko juga harus menjadi tempat yang disegani oleh wisatawan karena merupakan keunikan dan dapat menjadi daya Tarik wisatawan. Sehingga wisatawan tidak hanya berkunjung ke tempat tempat yang itu itu saja melainkan dapat datang ke tempat lain yang sama unik dan bagus.

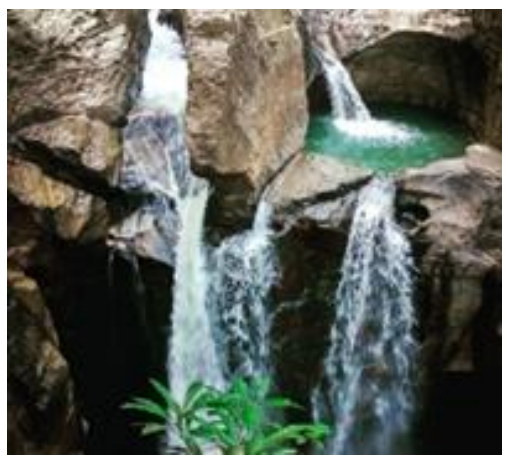

\section{Gambar 3 Cunca Wulang}

Selain cunca wulang, tempat wisata lain adalah Bukit Amelia Sea. Bukit Amelia Sea adalah bukit yang dapat digunakan untuk melihat sunset dan cocok pada sore hari. Di Bukit Amelia Sea kita harus menempuh perjalanan selama 15 menit serta mendaki selama 15 menit agar sampai ke puncak.

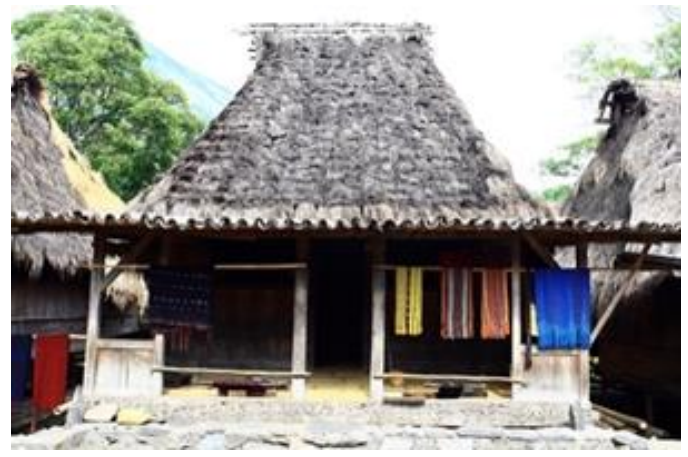

Gambar 4 Kampung Bena

Pada gambar 5 merupakan pantai pink yaitu pantai yang memiliki keunikan pasir yang berwarna pink. Wisatawan sangat senang mengunjungi pantai pink untuk melakukan snorkeling maupun hanya berjemur dan berjalan di sisi pantai. Tetapi hanya wisatawan asing yang lebih banyak datang dibandingkan wisatawan lokal.

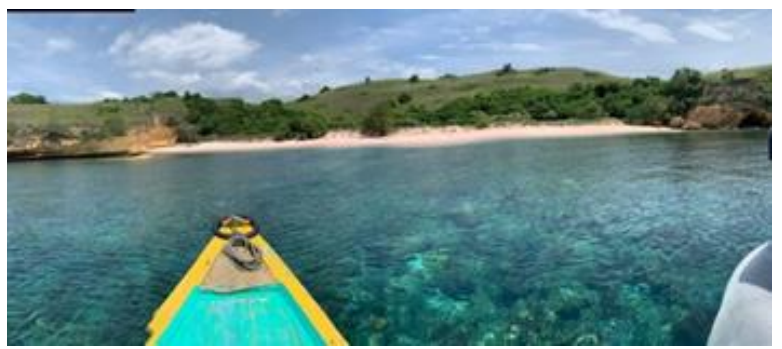

Gambar 5 Pantai Pink

\section{Uji Coba Aplikasi Sistem Pakar kepada User yang Gemar Travelling}

Uji coba ini adalah bagian dari peneliti melakukan kesimpulan dari 40 users yang suka melakukan travelling. Pada tahap ini dilakukan dari tanggal 1-April-2020 - 2-April-2020. Uji coba ini users menjalankan apps yang melakukan rekomendasi pada tempat wisata di Labuan Bajo dan dapat memberikan hasil diagnosa atau analisa terhadap tempat wisata yang user dapatkan. 
Peneliti melakukan testing prototype kepada users untuk dapat menggunakan apps dan melakukan analisa terhadap jenis tempat wisata yang diinginkan melalui Smartphone berbasis iOS. Pengguna dapat menjawab berbagai macam pertanyaan, setelah menjawab pertanyaan, kemudian aplikasi mengarahkan ke halaman hasil diagnosa dan solusi dari kebingungan tempat wisata yang ingin user kunjungi. Kemudian sistem pakar ini dapat menganalisa jenis tempat wisata hasil analisa aplikasi yang telah dilakukan dapat dilakukan perbandingan antara apps dengan pakar sudah sesuai yang telah diobservasi. Proses pengujian apps yang telah selesai, peneliti membagikan kuesioner secara online untuk melihat kepuasan user yang telah menggunakan aplikasi Wisata Labuan Bajo.

\section{Kesimpulan}

Proses pembuatan pohon keputusan berdasarkan hasil dari wawancara dan observasi kepada pakar. Hasil yang dibuat sudah sangat sesuai dengan apa yang didaptkan dengan knowledge pakar dan aplikasi ini mampu membantu user yang menggunakan agar lebih bisa terbantu dalam pemilihan tempat wisata.

\section{Saran}

Pemberian informasi tentang hasil diagnosa dan solusi lebih diperluas. Agar user mampu terbantu dengan adanya aplikasi ini yang ditujukan untuk membantu memilah tempat wisata mana yang baik di Labuan Bajo.

\section{Referensi}

Apple. (2015, April 3). Mengenai Pembaruan Xcode untuk OS X Server (Mavericks). Retrieved from https://support.apple.com/id-id/HT202925

Apple. $(2019,18)$. Mendapatkan bantuan untuk pembaruan iOS secara nirkabel. Retrieved December 16, 2019, from https://support.apple.com/id-id/HT201435

Badan Pusat Statistik Kabupaten Manggarai Barat. (2019, August 16). Badan Pusat Statistik Kabupaten Manggarai Barat. Retrieved December 16, 2019, from https://manggaraibaratkab.bps.go.id/subject/16/p ariwisata.html

Dicky Nofriansyah, S. (2015). Konsep Data Mining Vs Sistem Pendukung Keputusan. Deepublish.

Herawan Hayadi, B., Bastian, A., Rukun, K., Jalinus, N., Lizar, Y., \& Guci, A. (2018). Expert System in the Application of Learning Models with Forward Chaining Method. International Journal of Engineering \& Technology, 7(2.29), 845. doi:10.14419/ijet.v7i
McGuinness, D. (2015, May 9). ES-Builder Web. Retrieved December 16, 2019, from https://www.mcgoo.com.au/html/esbuilder_web.php

Munaiseche, C. P., Kaparang, D. R., \& Rompas, P. T. (2018). An Expert System for Diagnosing Eye Diseases using Forward Chaining Method. IOP Conference Series: Materials Science and Engineering, 306, 012023. doi:10.1088/1757899x/306/1/012023

Putri, A. T., $\quad$ Santoso, B. S., $\quad$ Rabbani, M. H., $\quad \&$ Wulandari, L. (2014). Aplikasi Sistem Pakar Pendeteksi Kerusakan pada Smartphone. Seminar Nasional Teknologi Informasi dan Komunikasi, 419 - 428.

Tanamal, R. (2019). What Is The Most Influential Factor On Decisions Using Youtube As a Tool To Support Buy Or Sell Means? (Case Study Surabaya City And Surrounding Area). Jurnal Teknik Informatika dan Sistem Informasi, 97(20). 